\title{
Porto Murtinho, Mato Grosso do Sul, e o Corredor Bioceânico: caminhos possíveis para a sustentabilidade socioambiental
}

\author{
Porto Murtinho, Mato Grosso do Sul, y la Carretera Bioceánica: caminos \\ posibles para la sostenibilidad socioambiental
Porto Murtinho, Mato Grosso do Sul, and the Bioceanic Highroad Crossing: possible paths for socio-environmental sustainability

\author{
Maristela Benites ${ }^{1}$ \\ Simone Mamede ${ }^{2}$ \\ Carla Villamaina Centeno ${ }^{1}$ \\ Gilberto Luiz Alves ${ }^{2}$
}

\begin{abstract}
Recebido em 23/02/2019; revisado e aprovado em 13/04/2019; aceito em 21/06/2019
\end{abstract}
DOI: http://dx.doi.org/10.20435/inter.v20iespecial.2413

\begin{abstract}
Resumo: Este trabalho tem por objeto o município de Porto Murtinho, localizado na porção sudoeste de Mato Grosso do Sul. Objetiva analisar a economia local e seu reflexo na biodiversidade nas últimas décadas, além de sondar possíveis impactos da implantação do Corredor Bioceânico, tendo como pressupostos o desenvolvimento sustentável, o reconhecimento e a valorização da cultura, do ecoturismo, do turismo de observação de aves e da vida selvagem.
\end{abstract}

Palavras-chave: desenvolvimento sustentável; fronteira; turismo; cultura; economia.

Resumen: Este trabajo tiene por objeto el municipio de Porto Murtinho, ubicado en la porción suroeste de Mato Grosso do Sul. Objetiva analizar la economía local y su reflejo en la biodiversidad en las últimas décadas, además de sondear posibles impactos de la implantación de la Carretera Bioceánica, teniendo como presupuestos el desarrollo sostenible y el reconocimiento y valorización de la cultura, el ecoturismo, el turismo de observación de aves y la vida silvestre.

Palabras clave: desarrollo sostenible; frontera; turismo; cultura; economía.

Abstract: This work aims at the municipality of Porto Murtinho, located in the southwest portion of Mato Grosso do Sul. It aims to analyze the local economy and its reflection on biodiversity in the last decades, besides probing possible impacts of the implementation of the Bioceanic Highroad Crossing, having as presuppositions the sustainable development and the recognition and appreciation of culture, ecotourism, bird-watching and wildlife tourism.

Keywords: sustainable development; frontier; tourism; culture; economy.

\section{INFORMAÇÕES HISTÓRICAS SOBRE PORTO MURTINHO}

Porto Murtinho é um município muito peculiar, tanto do ponto de vista socioeconômico quanto do ambiental. Sua economia experimentou quatro momentos expressivos. Inicialmente o da erva-mate, seguido da exploração do tanino e, por fim, o da pesca, sendo a pecuária desenvolvida simultaneamente a todas. Sua origem deveu-se à Companhia Mate Laranjeira, quando essa empresa se organizou como sociedade por ações. Sua localização foi considerada apropriada para a implantação de um porto, às margens do Rio Paraguai, que facilitava o escoamento da erva-mate para o mercado externo.

A construção do porto foi acompanhada de outras obras de infraestrutura e logística para facilitar a cadeia produtiva da erva-mate. A partir desse porto passou a ser realizada a exportação

\footnotetext{
${ }^{1}$ Universidade Estadual de Mato Grosso do Sul, Campo Grande, Mato Grosso do Sul, Brasil.

2 Universidade para o Desenvolvimento do Estado e da Região do Pantanal, Campo Grande, Mato Grosso do Sul, Brasil.
} 
da erva-mate para a Argentina, principal consumidora. Por força e influência política de Joaquim Murtinho, ministro da fazenda do presidente Campos Sales (1898-1902), no final do século XIX, o nome do município veio a homenageá-lo. Sua emancipação político-administrativa ocorreu a 13 de junho de 1912. Em 1943 fez parte do Território Federal de Ponta Porã, extinto em 1946.

A Guerra da Tríplice Aliança (1864-1870) foi um evento marcante no passado do município. Até meados do século XX, um século após o final da Guerra, não era raro moradores encontrarem artefatos intactos do grande conflito e vestígios materiais ainda podem ser encontrados em áreas remotas ou naquelas pouco modificadas desde aquela época. A navegabilidade do Rio Paraguai foi desde os primórdios, e continua, alvo do interesse econômico do colonizador e explorador, de investidores e do mercado em geral, o que suscitou movimentos conflitantes de disputa por domínio territorial. Assim, ao longo da história, em virtude do porto fluvial que articulava Mato Grosso à bacia do Prata por meio das trocas, Porto Murtinho se tornou um entreposto logístico importante no extremo sul do Estado. O município é um repositório da riqueza material granjeada nas fases econômicas da erva-mate, da pecuária, do tanino e da pesca.

Em contextos culturais, o município mantém, desde longa data, estreita integração com o Paraguai. Além do trabalho, do folclore, dos festejos populares, da música e de outras formas de arte, também na culinária se difundiu o consumo da chipa, da sopa paraguaia, do lambreado, do vori-vori e do puchero. Essas práticas culturais revelam a singularidade plasmada pelo processo histórico na materialidade do território. O idioma é uma junção e sobreposição da língua portuguesa, do guarani e do espanhol (castelhano), marcando singularmente a condição de fronteira com o Paraguai.

O singular e o universal estão fortemente interligados nesses processos. Apesar da singularidade sociocultural e ambiental patentes, os movimentos do capital atendem aos modos de reprodução da sociedade capitalista em âmbito mundial.

A singularidade cultural de certo espaço definido não exclui o universal, a sociedade capitalista, nem a adaptação de tradições passadas de seus habitantes ou as imposições do meio geográfico aos ditames do capital, que se amalgamaram numa forma única de ser. (ALVES, 2014, p. 41).

$E$, ainda que as tradições culturais não sejam comuns a todo o contingente populacional do lugar, em alusão, por exemplo, a imigrantes, o sistema de técnicas e sistema de ações conformam as formas de produção do espaço geográfico, tornando-as convergentes entre os moradores e sintonizados à base material. Isto demonstra novamente a expressão do universal sobre o singular e sua ação recíproca.

O lugar, palco do cotidiano onde as relações sociais são mais próximas e a produção do espaço tem algo de comum, o sentimento de vínculo efetivo não é o elemento ou a variável causadora das relações sociais, mas a materialidade dos objetos, técnicas e ações é que vão gerar a construção do espaço geográfico comum. (SANTOS, 2012, p. 321).

Este trabalho tem por objeto o município de Porto Murtinho e objetiva analisar a economia local e seu reflexo na biodiversidade nas últimas décadas, além de sondar possíveis impactos da implantação do Corredor Bioceânico, tendo como pressupostos o desenvolvimento sustentável, o reconhecimento e a valorização da cultura, do ecoturismo, do turismo de observação de aves e da vida selvagem. O estudo faz uso de fontes primárias, de dados secundários oriundos de órgãos governamentais e de relatos de moradores. 


\section{CARACTERIZAÇÃO FÍSICA}

A compreensão dos aspectos fisiográficos de um espaço geográfico se faz importante porque, dentre outras implicações, o meio natural condiciona o modo de vida da sociedade e o ser humano, ao atuar sobre o meio, o transforma e ambos interagem recíproca e dialeticamente no espaço e no tempo.

Baseado em características paisagísticas e geomorfológicas, Porto Murtinho também se destaca no cenário estadual e nacional. É o único município brasileiro a apresentar atributos biológicos e paisagísticos que o caracterizam, definitivamente, como integrante do Chaco. No Brasil o Chaco recebe o nome de Pantanal. O IBGE, no mapa de vegetação (IBGE, 2012) descreve a presença de várias fitofisionomias chaquenhas. No Sistema Brasileiro de Classificação da Vegetação (IBGE, 2012) o Chaco está classificado como Savana Estépica e subdividido nas fitofisionomias Savana Estépica Florestada (formação florestal densa - mata chaquenha), Savana Estépica Arborizada (formação florestal chaquenha mais aberta), Savana Estépica Parque (formação vegetacional composta predominantemente pela palmeira carandá, Copernicia alba, cujo adensamento é regionalmente denominado carandazal) e Savana Estépica Gramíneo-lenhosa (campos nativos secos ou inundáveis, com plantas herbáceas e arbustivas lenhosas).

O IBGE (2012) considera que até agora, no Brasil, pouco foi acrescentado ao mapa fitogeográfico de Martius, anexado ao volume 21 da obra Flora brasiliensis (1858), a não ser três novas regiões florísticas, uma delas a do Chaco Boreal, conferida na flora do Mato Grosso do Sul. A título de referência, o naturalista von Martius (1840-1906) indicou cinco regiões florísticas brasileiras, a saber: Nayades (flora amazônica), Hamadryades (flora nordestina), Oreades (flora do Centro-Oeste), Dryades (flora da costa atlântica) e Napaeae (flora subtropical).

A formação savana estépica, ligada à província fitogeográfica do Chaco, compreende 520.000 km² (46\%) na Argentina, 230.000 km² (32\%) no Paraguai, 90.000 km² (15\%) na Bolívia e 9.000 km² (7\%) no Brasil (SILVA et al., 2008). A vasta planície quaternária entre os rios ParaguaiParaná e as montanhas pré-andinas ocidentais, conhecida como Gran Chaco, é uma região natural de $700 \mathrm{~km}$ de largura na direção Leste-Oeste e aproximadamente $1.500 \mathrm{~km}$ de norte a sul, compreendendo uma área estimada entre 800.000 e $1.000 .000 \mathrm{~km}^{2}$, onde predomina vegetação com características xeromórficas: plantas espinescentes, caducifólias e micrófilas, com abundância de cactos e bromélias (SARMIENTO, 1972; PRADO, 1993; SILVA et al., 2008; POTT; POTT; DAMASCENO-JÚNIOR, 2011).

No extremo leste da província chaquenha está o Rio Paraguai (PRADO, 1993) ao sul do Pantanal em território brasileiro, nas sub-regiões de Porto Murtinho e Nabileque, constituindo o Chaco úmido (PRADO et al., 1992; SILVA et al., 2008; SILVA; CAPUTO, 2010). As florestas dominadas por quebracho-vermelho (Schinopsis balansae), os quebrachais, na porção nordeste da Argentina e Paraguai, as quais penetram no território brasileiro, em Porto Murtinho, atribuem características irrefutáveis do bioma Chaco, ainda que em área pequena (PRADO et al., 1992; PRADO, 1993).

Essa região está circunscrita também à planície do Pantanal, uma vasta depressão aluvial do Alto Paraguai, situada no centro-sul da América do Sul, entre os domínios do Chaco, Cerrado e da Pré-Amazônia, com presença também de componentes bióticos da Caatinga e de florestas estacionais (AB'SABER, 2006; POTT; POTT; DAMASCENO-JÚNIOR, 2009). Por sua posição transicional entre domínios morfoclimáticos e fitogeográficos, Aziz Ab’Saber considera o Pantanal 
como uma paisagem de exceção. O Rio Paraguai, responsável pelo regime de inundações na planície, integra a Bacia Platina, considerado o quinto maior sistema de drenagem do mundo e o segundo da América do Sul, superado apenas pela Bacia Amazônica (ASSINE; SILVA, 2009).

As estações do ano são bem definidas em período de seca e cheia, assim como em outras regiões do Pantanal. De novembro a março, com a chegada das chuvas, o nível das águas aumenta, alagando, em período subsequente, grandes áreas e influenciando, decisivamente, o ritmo de vida humana e não humana. Embora as inundações sejam frequentes no Pantanal, as mesmas não são regulares, delineando ciclos plurianuais e variações interanuais que mantêm a imprevisibilidade do tempo de duração das cheias. A partir da década de 1970 um novo ciclo de cheias tornou-se frequente no Pantanal. Ciclos plurianuais alternados de intensa seca ou cheia, se tornaram fenômenos naturais observáveis a partir desse período.

Em 1982, após alguns anos de significativas enchentes, a cidade de Porto Murtinho foi atingida por enchente de intensidade superior às demais históricas, o que levou à proposição mitigatória de construção de um dique de contenção, consumado em 1985 . O dique tem 10,5 quilômetros de extensão e altura de 11 metros, e circunda todo o perímetro urbano. Quando aumenta o nível altimétrico do Rio Paraguai, a água pluvial é escoada por meio de um sistema de bombeamento. Porto Murtinho, localizada à margem esquerda do Rio Paraguai, é considerada a única cidade brasileira a possuir um dique de contenção de enchentes, neste caso, do Rio Paraguai. Até a inauguração do dique, os moradores precisavam se mudar, temporariamente, para o acampamento improvisado no $\mathrm{km} \mathrm{10,} \mathrm{conhecido} \mathrm{por} \mathrm{"cidade} \mathrm{de} \mathrm{lona".}$

Todas as fontes hídricas da Bacia do Alto Paraguai drenam para o Rio Paraguai, responsável pelas simbólicas cheias do Pantanal. O Fecho dos Morros, localizado ao norte de Porto Murtinho, é um dos principais elementos estruturais orográficos responsáveis pelo estreitamento do Rio Paraguai e represamento das águas. Devido à baixa declividade topográfica da planície pantaneira, naturalmente há baixo poder de vazão das águas, e, na presença do Fecho dos Morros, o escoamento da água se torna ainda mais lento.

\section{3 ÁREAS PROTEGIDAS}

As áreas protegidas no Brasil são denominadas unidades de conservação. Esses territórios, que não devem ser confundidos com propriedades rurais, são espaços instituídos pelo poder público com objetivo de proteção da biodiversidade, conforme dispõe o Sistema Nacional de Unidades de Conservação (SNUC) (BRASIL, 2000). O território de Porto Murtinho integra parte do Parque Nacional da Serra da Bodoquena, a Área de Proteção Ambiental (APA) do Rio Perdido e um pequeno parque, o Parque Natural Municipal Cachoeira do Apa, num total de 60.907,95 hectares dos 1.773 .500 hectares que perfazem a superfície territorial do município, ou seja, as unidades de conservação não alcançam $4 \%$ do território.

Interessante notar que nenhuma dessas unidades de conservação contempla áreas específicas do Chaco. Além disso, as categorias de unidade de conservação em Porto Murtinho não oferecem as mesmas condições de proteção entre si. As APAs, por exemplo, unidades de conservação de uso sustentável são pouco efetivas na função de salvaguardar a biodiversidade contida em seus limites, visto que os critérios de proteção são bastante flexíveis, o que torna frágil, de certa maneira, a sua eficiência. O quadro 1 mostra a extensão territorial das unidades de conservação em Porto Murtinho. 
Quadro 1 - Número de Unidades de Conservação de Porto Murtinho, MS

\begin{tabular}{|l|c|c|}
\hline Unidade de Conservação & Grupo & Extensão (hectares) \\
\hline APA do Rio Perdido & Uso sustentável & $36.145,59$ \\
\hline Parque Natural Municipal da Cachoeira do Apa & Proteção Integral & 58,2450 \\
\hline Parque Nacional da Serra da Bodoquena & Proteção Integral & $24.703,36$ \\
\hline Total & & $60.907,95$ \\
\hline
\end{tabular}

Fonte: Imasul (s.d.).

Pela inexistência de unidades de conservação para proteção dos remanescentes de Chaco no Brasil, a vulnerabilidade deste bioma é preocupante. Além de áreas protegidas, observa-se a necessidade da integração de corredores ecológicos e de biodiversidade transnacionais envolvendo Argentina, Bolívia, Brasil e Paraguai, de forma a assegurar a efetividade de proteção da biodiversidade chaquenha. Cabe ressaltar, que o município de Porto Murtinho contempla a Terra Indígena Kadiwéu, área demarcada em 1984, através do Decreto no 89.578/1984.

\section{CONTEXTO HISTÓRICO DO MUNICÍPIO E SEUS CICLOS ECONÔMICOS}

Porto Murtinho construiu história semelhante aos demais municípios que tiveram contato com a exploração comercial da erva-mate na Bacia Platina (OLIVEIRA; ESSELIN, 2015). O município foi criado para servir de escoadouro da indústria extrativista da erva-mate (Ilex paraguariensis), referida como o "ouro-verde do Sul" em oposição ao ouro da região mais ao norte do país. Lefebvre (2001), afirma que cidades e indústrias se instalam próximas a fontes de energia (rios, florestas etc.), visto ser a base do trabalho e de existência material.

O empreendimento de logística dispendiosa com carretas puxadas a bois por longas distâncias e em estradas precárias até à sede da Companhia, em Concepción no Paraguai, motivou a adoção de via alternativa e a erva passou a ser embarcada no porto construído pela Companhia Matte Larangeira em Porto Murtinho. Embora o município não tivesse plantações nativas de erva-mate, incorporou-se à cadeia produtiva ervateira quando passou a ser o porto navegável e local de transbordo da erva-mate (SILVESTRINI; WEINGARTNER; TACHIBANA, 2018).

Os trabalhadores, sobretudo os camponeses paraguaios, vivendo em seu país os horrores e mazelas de um final de guerra, tentavam buscar meios para sua sobrevivência. Ao perderem suas terras pela exploração do capital, eram empregados pelas empresas da região, principalmente as ervateiras, num sistema conhecido por escravidão de dívidas (CENTENO, 2008). A autora afirma que esse mesmo sistema de exploração da força de trabalho foi utilizado pela Companhia Matte Larangeira, a qual passou a exercer forte controle político e econômico na região. Além da concessão, fez contratos de arrendamento com proprietários locais, monopolizando a exploração até a década de 1940. Embora a exploração da erva-mate fosse realizada por pequenos produtores em menor escala, os mesmos acabavam dependentes da Companhia, vez que ela detinha o controle do transporte e assim estabelecia, soberanamente, os preços na comercialização.

Indígenas da região também foram incorporados ao trabalho nos ervais como alternativa de suposto trabalho assalariado e na forma de exploração abusiva (BRAND; FERREIRA; ALMEIDA, 2005). Segundo Oliveira e Esselin (2015), a economia ervateira prosperou em função, também, da exploração do território, da força de trabalho e do conhecimento de milhares de indígenas, 
cujos antepassados mais antigos estabeleceram-se na bacia hidrográfica do Rio da Prata há pelo menos 2 mil anos.

A exploração da erva-mate no antigo sul de Mato Grosso foi uma atividade viabilizada para dinamizar a economia e assegurar a definitiva incorporação da região ao território nacional do Brasil. Para isso também foi providenciada a exploração do território, da mão de obra e do conhecimento de comunidades guarani e kaiowá ali estabelecidas. Portanto, durante décadas os índios também participaram ativamente da economia regional, embora na condição de subalternidade. Por este motivo, nem sempre aparecem como trabalhadores nacionais em fontes oficiais e na historiografia tradicional de viés colonialista. (OLIVEIRA; ESSELIN, 2015, p. 311).

Além da redução do plantio na década de 1940, a Argentina, grande importadora de erva-mate, apresentava crescimento vigoroso de suas plantações e produção, habilitando-se também na produção. Na mesma época, o governo de Getúlio Vargas (1930-1945) passou a rever as concessões de terras em Mato Grosso, atingindo frontalmente a Companhia que monopolizava grandes extensões (CENTENO, 2008).

Como o capitalismo se reinventa frente às adversidades, especialmente na presença de abundantes recursos naturais, e cria novos substratos de ação, em 1935, já em período de decadência da exploração dos ervais, o alvo se tornou o tanino. A Florestal Brasileira S.A. substituiu a Taninos em Porto Murtinho e foi fundada em consórcio do governo alemão, com aplicação, portanto, de capital estrangeiro. Iniciou suas atividades em 1936 para exploração do tanino, uma resina vegetal que se constituía em matéria-prima utilizada na indústria química, no curtume e na tecelagem (CORRÊA; CORRÊA, 2009). As madeiras exploradas eram principalmente quebracho-vermelho (Schinopsis balansae), também conhecido por coronillo e la hembra, e aroeira ou urunde'y (Myracrodruon urundeuva).

Essa atividade surgiu na região da bacia do Prata, articulada à pecuária e aos seus subprodutos, em especial, couros bovinos e peles de animais silvestres. Isto porque o tanino foi o principal insumo no processo de beneficiamento de couros, largamente utilizado por curtumes platinos e destinou-se também aos estabelecimentos do Rio Grande do Sul e de outros mercados nacionais e estrangeiros. (CORRÊA; CORRÊA, 2009, p. 55).

Parte da infraestrutura construída na época da erva-mate foi mantida para a produção e escoamento do tanino. O trem, por exemplo, que ligava a fazenda São Roque ao porto e percorria a linha férrea de $22 \mathrm{~km}$, passou a ser utilizado para o transporte de madeira até à fábrica de processamento. Também revezava no transporte de madeira e no abastecimento semanal de água à vila dos trabalhadores. No relato de Matilde Benites:

Toda terça-feira passava o trem que levava água na vila. Quem tinha tambor e morava perto da linha já deixava ali. E quem morava longe precisava carregar até a linha e depois levava de volta. Esse era o jeito que a gente tinha para ter água.

Em funcionamento a Florestal chegou a empregar cerca de duas mil pessoas que trabalhavam na administração e contabilidade, extração e industrialização do tanino, cujo processo de produção envolvia a trituração da madeira e outros procedimentos para dar origem ao produto final. Contam os trabalhadores que o trabalho pesado rendia acidentes na fábrica pela manipulação e envase do produto a altas temperaturas e também no transporte até as embarcações. Nos campos extrativos o trabalho braçal também era intenso e sem interrupções, mesmo sob condições ambientais adversas de uma planície alagável, com presença de mosquitos e calor 
abrasador. Além disso, não havia preocupação com reposição da madeira retirada, a ordem era apenas extrair.

Atualmente, o quebracho-vermelho é considerado espécie da flora brasileira ameaçada de extinção e a aroeira deixou de integrar a lista oficial brasileira de espécies ameaçadas somente na última publicação de 2014 (BRASIL, 2014). Para Corrêa e Corrêa (2009) um dos fatores que levaram à decadência da exploração comercial de tanino foi a retirada extensiva e predatória das matas de quebracho, sem manejo adequado e total falta de investimentos na sustentabilidade dessa atividade.

A erva-mate saiu de cena definitivamente na década de 1940 e deixa de ter importância para a economia regional. Mas nesse período já havia produção bovina. O mesmo acontece com o tanino, isto é, a produção de gado bovino, ainda que pequena, se comparada aos dias atuais, estava presente como matriz complementar e como elemento de influência sociocultural. No regime pastoril, assim considerado por Sodré (1941), sempre que acaba um ciclo vem a pecuária em substituição, como um plano econômico alternativo.

A ocupação da primeira frente pioneira no Pantanal se deu na década de 1830 com a vinda dos mato-grossenses em direção ao sul (ESSELIN, 2011). Todavia, a origem da pecuária no sul de Mato Grosso ocorreu ainda nos séculos XVI e XVII por iniciativa de colonos espanhóis e missionários da Companhia de Jesus. Segundo Esselin (2011), nesse período tanto colonos quanto jesuítas importavam rebanhos bovinos de Assunção, os quais desempenhavam papel relevante nos núcleos habitacionais, quer como fontes de proteína ou como animais de tração para a lide cotidiana. Mais tarde, com a primeira Guerra Mundial e o crescimento da demanda por alimento, as charqueadas, que eram mantidas para o abastecimento doméstico e dos empregados, transformaram-se em fonte de abastecimento para o mercado europeu, no mesmo período em que essa cadeia ruía no Uruguai e Argentina, seus polos tradicionais de produção, os quais passaram a manter frigoríficos (ALVES, 2005, p. 46). A pecuária ganha outra dimensão no Sul do Mato Grosso e os saladeiros lançam sua projeção comercial.

Os saladeiros aproveitavam todas as partes do boi abatido, a carne, a couro, o osso, o chifre, a gordura, o casco etc. Um desses estabelecimentos, de propriedade de empresários uruguaios se localizava no município de Porto Murtinho: o Saladeiro Barranco Branco, que hoje sedia o destacamento militar do Exército Brasileiro, Destacamento Barranco Branco. Outro saladeiro localizado na área urbana hoje conhecido por Saladêro Cuê também alcançou destaque nacional com a industrialização do charque (LIMA, 2000). Em Porto Murtinho a indústria do charque e funcionamento dos saladeiros duraram até a década de 1960, quando encerraram suas atividades. Assim, o gado sempre esteve presente na estrutura social e econômica murtinhense, embora com pouca força inicial, algo diferente do quadro atual, cuja produção é a principal matriz econômica do município.

Na década de 1980 teve início o turismo de pesca. Porto Murtinho possui o cenário considerado ideal para a pesca. O turismo de pesca foi um segmento bastante desenvolvido em passado recente de Porto Murtinho e que proporcionava emprego e renda. Até hoje, muitas famílias dependem da movimentação econômica da alta temporada desse segmento turístico. Nesse período, Porto Murtinho recebe turistas de várias partes do país, principalmente das regiões sul, sudeste e centro-oeste do Brasil. A mesma tem início no mês de fevereiro, tendo como modalidade a pesca esportiva (pesca e solte) e, no início de março, a pesca profissional e amadora estendendo-se até início de novembro, quando começa a Piracema, período de defeso. 
Devido ao esgotamento do pescado, em decorrência de falta de gestão adequada e de exploração sustentável, mais uma vez Porto Murtinho e a fronteira se veem em declínio econômico. Toda a rede hoteleira tem sofrido com a baixa procura de turistas e, não somente isso, muitos barcos-hotéis que são grandes embarcações oferecem logística completa desde hospedagem ao consumo de alimentos e bebidas, o que enfraquece ainda mais o comércio local. Junto ao turismo de pesca veio o turismo sexual envolvendo crianças e adolescentes, com denúncias em mídias e noticiários regionais e de longo alcance.

Desse modo, é possível delinear os períodos de desenvolvimento econômico e seus declínios correspondentes (Figura 1).

Figura 1 - Representação esquemática das fases econômicas vividas por Porto Murtinho, MS

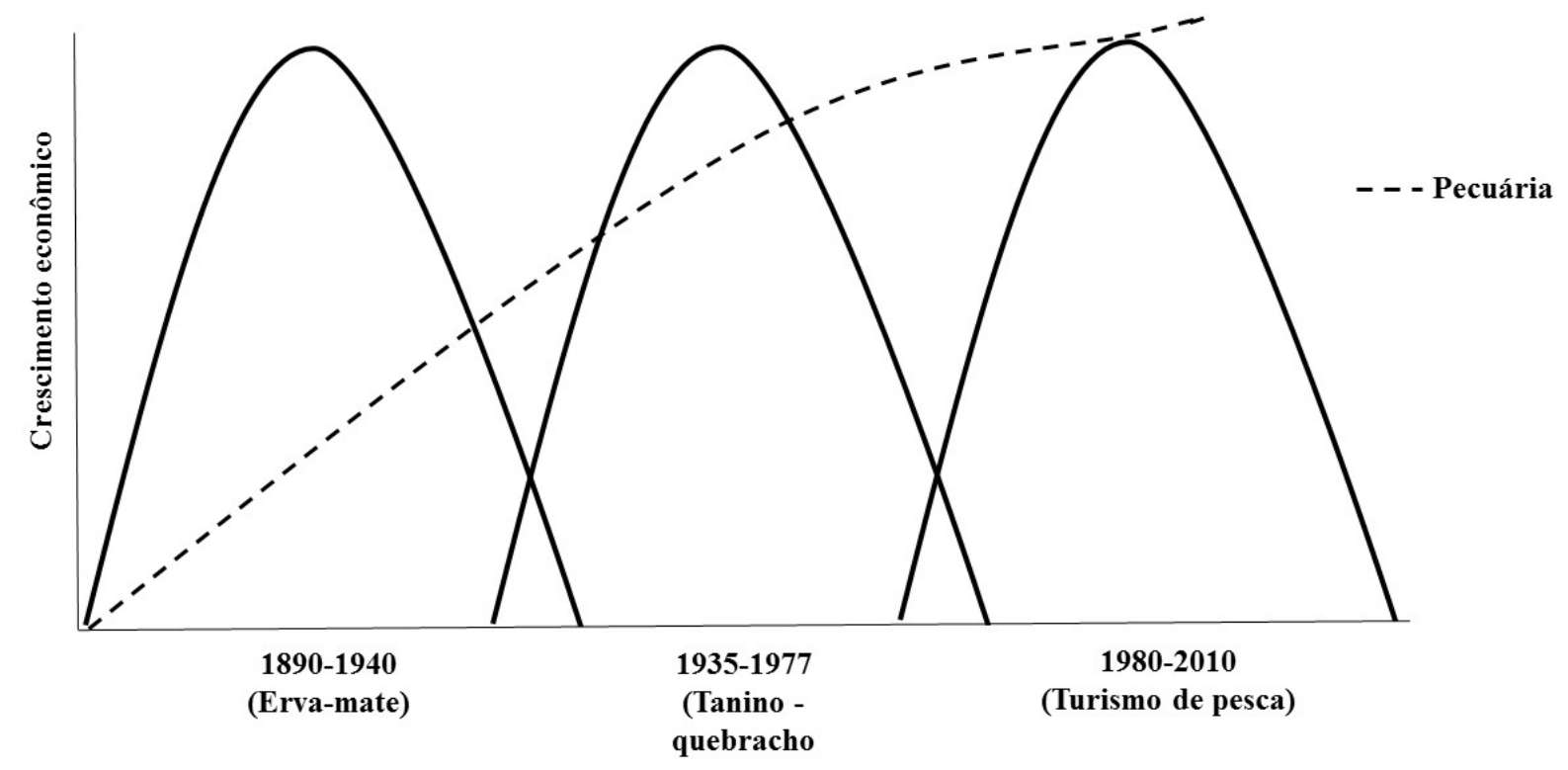

Fonte: Elaborado pelos autores.

A sociedade como um todo erra ao pensar que o ser humano é o elemento central de tudo, portanto, pode dispor dos bens naturais de forma deliberada e não planejada, na forma de instrumentalização da natureza. No entanto, toda a fonte de produção é provida pela natureza, ou melhor, pela biodiversidade, e há necessidade imperativa de uso sustentável. Porto-Gonçalves (2012), afirma que nenhum país ou sociedade produz ferro, petróleo ou água. A sociedade é extrativista, portanto precisa gerir melhor seus recursos naturais. Em Porto Murtinho, a falta de sustentabilidade no uso dos bens naturais que impulsionaram o desenvolvimento socioeconômico levou a matéria-prima à exaustão, sob a forma de dominação exacerbada da natureza. Segundo Porto-Gonçalves (2012), nas relações de dominação todo ser que é dominado não é respeitado pela sua existência, nas suas virtualidades e potencialidades, vez que é considerado somente nas qualidades úteis ao dominador.

A figura 2 apresenta algumas imagens do que restou da fábrica de tanino, atual fazenda Quebracho, e o trem, atual monumento histórico instalado na praça da cidade. 
Figura 2 - Imagens das ruínas do pátio de produção de tanino na fazenda Quebracho (à esq.) e o trem utilizado no transporte de madeira (à dir.). Na foto, Sra. Matilde Benites e Sr. Augusto Soares da Silva, naturais de Porto Murtinho. Sr. Augusto foi maquinista do trem para transporte de quebracho

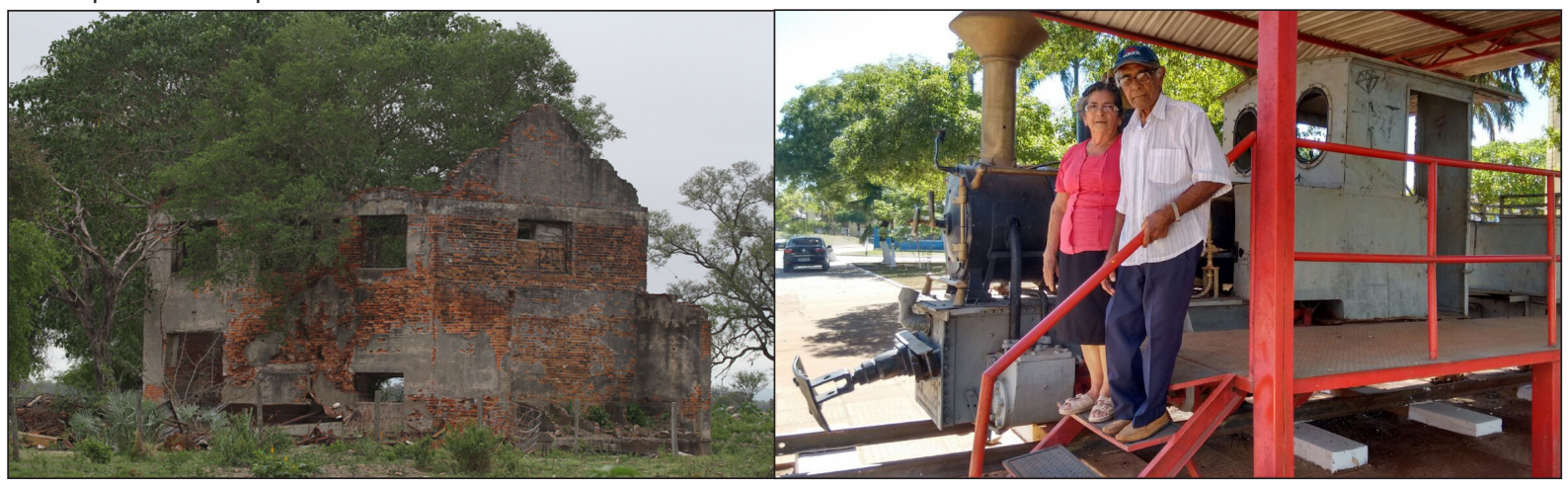

Fotos: Acervo dos autores.

\section{CONTEXTO FRONTEIRIÇO}

Há muita especificidade local em Porto Murtinho. O município faz fronteira com o Paraguai e divisa com os municípios brasileiros Corumbá, Miranda, Bonito, Jardim e Caracol. As relações podem parecer lógicas, mas demasiadas complexas. Até 2000, por exemplo, não havia ligação rodoviária por meio de pavimentação asfáltica a cidades do próprio estado de Mato Grosso do Sul. Porto Murtinho se mantinha, portanto, desligada dos grandes centros urbanos, por essa via, incluindo a capital estadual, distante cerca de $450 \mathrm{~km}$. A BR-267, que corta grande parte da região Sudoeste, teve sua pavimentação asfáltica inaugurada em 2003 conectando os 200 km de Jardim a Porto Murtinho, divisa com a República do Paraguai. Historicamente, a população sempre desenvolveu relações econômicas, culturais e mesmo políticas com o Paraguai, marcando a representação de pertencimento regional e base cultural comum. Ainda que se tenha reduzido tal integração, em virtude de maior possibilidade de deslocamentos no Brasil ocasionada pela rodovia asfaltada, os laços continuam fortes com a cultura e economia paraguaias.

Porto Murtinho está entre os municípios brasileiros com maior superfície territorial. É o segundo maior município em extensão territorial do estado, com 17.744,41 km² e densidade populacional de 0,91 hab/ $\mathrm{km}^{2}$. Integra a Microrregião do Baixo Pantanal (SEMADE, 2016) e as sete cidades-gêmeas do estado, na fronteira com o Paraguai e com a Bolívia, conforme portaria do Ministério da Integração Nacional (Portaria no 213, de 19 de julho de 2016). Segundo esta política pública, são consideradas cidades-gêmeas as cortadas pela linha de fronteira seca ou fluvial, articulada ou não por obra de infraestrutura, que apresentem grande potencial de integração econômica e cultural, podendo ou não apresentar uma conurbação (relativa à área urbana formada por cidades e vilarejos que foram surgindo e se desenvolvendo um ao lado do outro, formando um conjunto) ou semiconurbação com uma localidade do país vizinho, assim como manifestações "condensadas" dos problemas característicos da fronteira, que aí adquirem maior densidade, com efeitos diretos sobre o desenvolvimento regional e a cidadania. De acordo com o Ministério da Integração Nacional, o estabelecimento do conceito de cidades-gêmeas serve para nortear políticas públicas para a região fronteiriça, dentre elas a instituição de uma zona livre de comércio em cada município. 
A vida modesta em Porto Murtinho segue o ritmo das águas do Rio Paraguai. Pela manhã, principalmente, é possível encontrar muitos trabalhadores paraguaios que atravessam o Rio Paraguai em embarcações, conhecidas por chalanas, para ocupação em seus postos de trabalho em Porto Murtinho e vice-versa. Várias senhoras paraguaias, por exemplo, levam plantas medicinais para comércio na feira livre no lado brasileiro, confirmando a detenção de conhecimento tradicional e de saberes etnobiológicos. E turistas aproveitam a travessia para contemplação da beleza cênica do Rio Paraguai e da planície pantaneira ou para compras no comércio paraguaio, que já fora intenso em épocas passadas. Chalaneiro ou chalaneira é uma profissão de muitos anos de atuação na fronteira. Sejam motorizadas ou movidas a remo, as chalanas, outrora de madeira, transportam pessoas e seus objetos em cumprimento ao seu cotidiano, e essa travessia motiva intercâmbio de saberes e intercâmbio sociocultural, fortalecendo as relações sociais na fronteira (Figura 3).

\section{Figura 3 - Chalaneiro em travessia no Rio Paraguai}

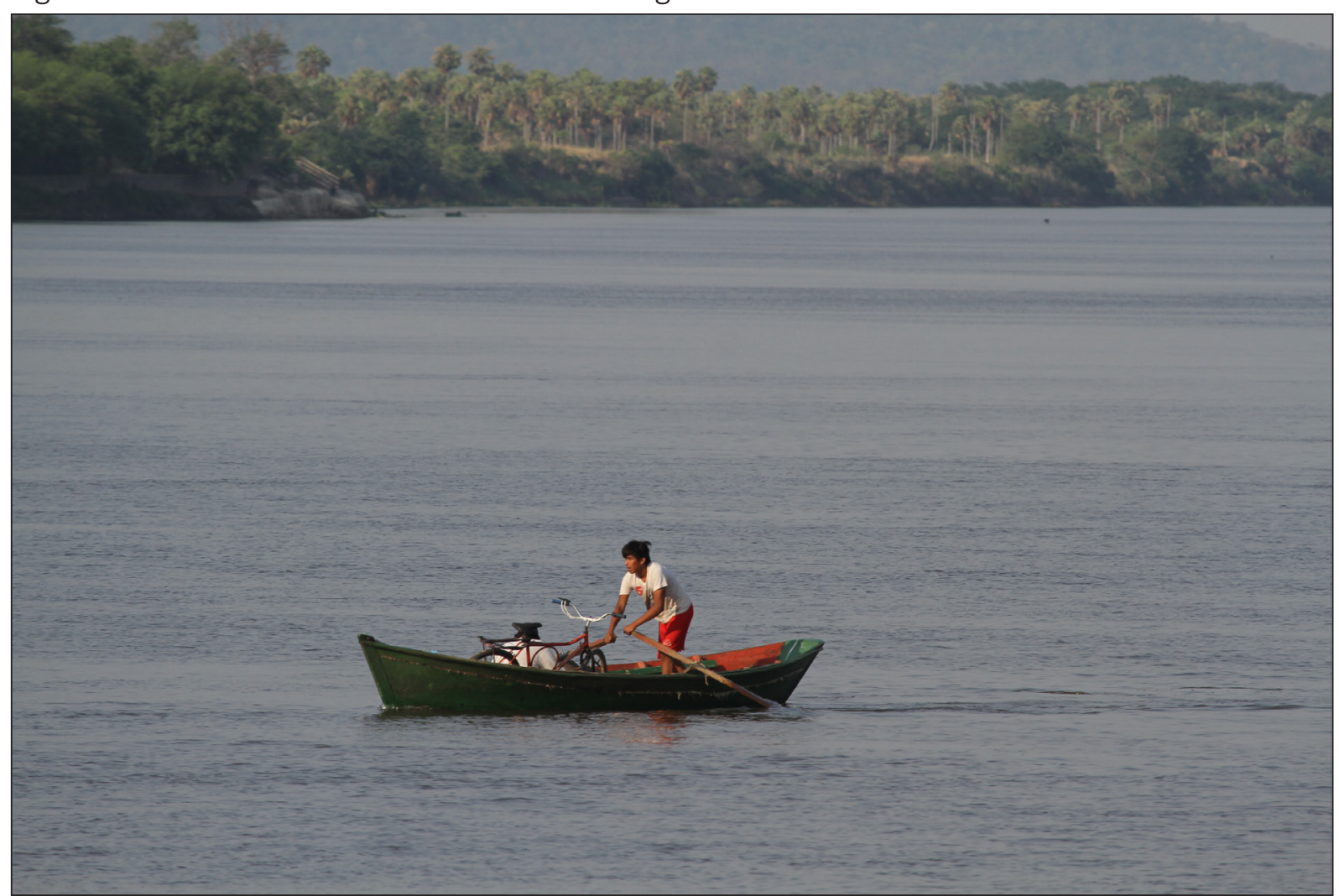

Foto: Simone Mamede.

\section{EDUCAÇÃO}

A educação em Porto Murtinho também é marcada por peculiaridades, dada a sua proximidade com o Paraguai. O idioma oficial é o português. No entanto, além da língua portuguesa, fala-se o castelhano e o guarani, marcando o hibridismo linguístico do lugar (ROMERO; RODRIGUES, 2014). Em 1912, apogeu da erva-mate no estado, as escolas na região eram muito precárias ou inexistentes, de modo que as crianças brasileiras, em grande parte, estudavam em escolas paraguaias (CENTENO, 2008). Com o Estado-Novo de Getúlio Vargas (1930-1945) a política de nacionalização do país era imperativa. A Cia Matte Larangeira era acusada de empregar mão 
de obra estrangeira e a lei exigia que 2/3 dela fosse nacional. Assim, a Matte contratou alguns trabalhadores desempregados em São Paulo e Rio de Janeiro, mas estes, segundo fontes oficiais, não conseguiram se adaptar ao trabalho e ao clima da região. O motivo da preferência pela força de trabalho paraguaia era devido ao custo mais baixo e à adaptação do trabalhador às condições locais, além de dominarem as especificidades e o processo de trabalho, já que o mesmo era ainda manufatureiro e necessitava do saber do trabalhador paraguaio (CENTENO, 2008). Mas a partir daí a escola passou a priorizar o ensino da língua portuguesa privando os alunos de falar outro idioma, ainda que os pais falassem naturalmente o guarani e/ou o castelhano no ambiente doméstico. Somente a partir do século XXI com as políticas educacionais recentes é que o ensino bilíngue em regiões de diversidade linguística passou a ser incentivado.

O município com 15.372 habitantes (censo demográfico de 2010) não oferecia nenhum curso superior até 2006. Quem quisesse continuar os estudos após o ensino médio tinha de se mudar para outra cidade como Campo Grande, a 450 km, ou se deslocar diariamente por pelo menos 200 km, como é o caso de Jardim, onde funciona uma unidade universitária da Universidade Estadual de Mato Grosso do Sul (UEMS). O polo da Universidade Aberta do Brasil (UAB), polo de Educação a Distância- EaD, passou a oferecer cursos de graduação da Universidade Federal de Mato Grosso do Sul (UFMS) em 2006. Os alunos eram, em sua maioria, adultos com mais de 30 anos de idade, acompanhando o padrão nacional. A unidade de ensino a distância abriu novas perspectivas para o município e fez com que muitos murtinhenses, após muitos anos de distanciamento da escola, tivessem a oportunidade de melhorar sua formação ingressando no ensino superior. O impacto dessa medida refletiu de forma bastante positiva, visto que permitiu melhorias no sistema de ensino local, ao agregar mais professores graduados.

Com relação ao Índice de Desenvolvimento da Educação Básica (IDEB), o município não está distante de outros considerados mais desenvolvidos no estado. De modo geral, o ensino fundamental em suas séries finais ( 8 ㅇ e 9o anos) apresentam valores baixos em todos os municípios pesquisados, mas, ainda assim, Porto Murtinho recebeu nota maior que Corumbá em 2017, município que também integra a Microrregião do Baixo Pantanal. O município ficou meIhor colocado também em comparação geral com Três Lagoas, mostrando que, nem sempre, os municípios mais populosos e desenvolvidos apresentam melhor índice de educação escolar.

Avaliando o nível educacional da população sul-mato-grossense, na faixa acima de 10 anos de idade, os dados do Censo Demográfico de 2010 (IBGE) mostram que 92,95\% dos habitantes do estado são alfabetizados, portanto, aponta a existência de 7,05\% de analfabetos naquela faixa etária. Entre as Microrregiões, a de Campo Grande apresenta o melhor coeficiente de alfabetização com 95,86\% de seus habitantes, seguido da Microrregião Baixo Pantanal constituída pelos municípios de Corumbá, Ladário e Porto Murtinho. No entanto é na Microrregião de Iguatemi que se encontra o menor coeficiente de alfabetização do estado, onde $87,8 \%$ são letrados, resultando em uma taxa de $12,2 \%$ de analfabetos (SEMADE, 2016).

\section{CORREDOR BIOCEÂNICO}

O Corredor Bioceânico pretende ajudar o Brasil e os países vizinhos a escoar a produção, especialmente commodities, até os portos do Chile, fazendo ligação com o Oceano Pacífico, o que encurtaria as atuais distâncias de 8 para 2 mil quilômetros. Atualmente, a exportação de produtos agrícolas do Brasil é feita via Oceano Atlântico, a partir de portos do Sudeste e Sul. No entanto, a logística de transporte não acompanhou o aumento da produção agrícola brasileira 
e tem sido apontada como um dos principais entraves para o êxito da cadeia produtiva. Com o crescimento das economias asiáticas nas últimas décadas, a travessia do Oceano Atlântico, poderá, aos poucos, deixar de ser a principal corredor logístico das exportações agrícolas brasileiras e de países vizinhos, e o Oceano Pacífico se apresenta como uma alternativa viável a esse escoamento (ALMEIDA; SELEME; CARDOSO-NETO, 2013).

O estudo da viabilidade de acesso aos portos do oceano Pacífico é uma iniciativa protagonizada por empresários brasileiros, paraguaios e argentinos, interessados em reduzir o percurso para os mercados asiáticos, cuja rota atual Atlântico/Índico alonga a distância em quase 8.000 km (LE BOURLEGAT, 2016). Essa via alternativa pode contribuir especialmente com produtores de soja localizados nas regiões mais distantes dos portos brasileiros, por exemplo, as regiões Centro-Oeste e Norte (ALMEIDA; SELEME; CARDOSO-NETO, 2013).

O corredor transoceânico se mostra como mais uma oportunidade de inserção aos processos de globalização que se prosperam no mundo pós-moderno. Contudo, é necessário considerar os riscos de se transformar os modos de produção do espaço em Porto Murtinho por meio da oferta e imposição de uma nova forma de produção, especialmente quando várias experiências econômicas já foram vivenciadas há pouco tempo. É preciso atentar para o fato de que o município possui várias potencialidades e vocações econômicas sustentáveis que não devem ser reduzidas a atender a uma cidade portuária. Todo impacto precisa ser medido coerentemente para verificar seus benefícios, riscos e danos, no caminho da conciliação entre produção e sustentabilidade social, econômica e ambiental para assegurar a Porto Murtinho equilíbrio socioeconômico no médio e longo prazo.

No mundo pós-moderno as ações são cada vez mais estranhas aos fins próprios do homem e do lugar. Daí a necessidade de operar uma distinção entre a escala de realização das ações e a escala do seu comando, pois muitas das ações que se exercem num lugar são o produto de necessidades alheias, de funções cuja geração é distante e das quais apenas a resposta é localizada naquele ponto preciso da superfície da Terra. E a escolha do homem comum, em muitas das ações que empreende, é limitada. (SANTOS, 2012, p. 80).

\section{PERSPECTIVAS DE SUSTENTABILIDADE}

Formas de desenvolvimento precisam ser pensadas e planejadas para o município com população estimada, em 2018, de 17.078 habitantes com vasta área territorial. A título de referência social, em 2016, segundo o IBGE, o percentual da população com rendimento nominal mensal per capita de até $1 / 2$ salários mínimos era de 40,4\%, posicionando o município em trigésimo lugar no estado. E a proporção de pessoas ocupadas, isto é, trabalhadores com ocupação remunerada, era de 7,3\% conferindo-Ihe a septuagésima quinta posição dentre os municípios sul-mato-grossenses. Por outro lado, o PIB o coloca no sexagésimo oitavo lugar no estado, ao mesmo tempo em que, nesse mesmo ano, Porto Murtinho possuía 691.092 mil cabeças de gado bovino, ocupando a quarta posição entre os principais municípios produtores do estado. Os dados apontam para a baixa equidade socioeconômica.

Como em outros cenários de países periféricos e ao reflexo do universal, o município apresenta baixo número de postos de trabalho disponíveis em contradição ao de trabalhadores, e onde há carência de capitais, mas abundantes bens naturais. E sua condição de fronteira o mantém no contexto singular. 
Na fronteira, lugar privilegiado dos contrastes e da violência, foram recriadas algumas formas atrasadas de exploração da terra e de seus recursos naturais, como também foram reinventadas formas escravistas de exploração do trabalho. Além do mais, sob o impulso da penetração de relações capitalistas e da ação de empresas exportadoras monopolistas da região platina, a fronteira mato-grossense desenvolveu uma economia periférica e dependente das demandas dos mercados. (CORRÊA; CORRÊA, 2009, p. 57).

São variadas as oportunidades para iniciativas econômicas sustentáveis que podem possibilitar tanto desenvolvimento econômico dessa região, respeito às comunidades locais e a conservação do meio ambiente. Dentre essas oportunidades destaca-se o ecoturismo. O usufruto do patrimônio natural e cultural de forma sustentável é a principal característica do ecoturismo, o qual incentiva sua conservação e busca a formação de uma consciência socioambiental por meio da interpretação do ambiente, com garantia de bem-estar das populações visitadas (BRASIL, 2010). Nessa perspectiva, vale ressaltar a importância de se incentivar modelos mais inclusivos e colaborativos envolvendo vários setores socioeconômicos, ao mesmo tempo longe da visão edênica de meio ambiente e menos concentradora de riquezas, inclusive aos atores de sempre.

Se os grandes hotéis e os resorts simbolizam a acumulação e concentração de capital no setor turístico, as pousadas ou os pequenos hotéis podem simbolizar novas imagens de um turismo menos concentrador e mais solidário, menos pasteurizado e mais atento à diversidade cultural. O turismo não somente mapeia territórios, mas cria territorialidades, pois define destinos, propõe roteiros, dando visibilidade a espaços até então invisíveis. (CORIOLANO, 2009, p. 5).

O turismo de observação de vida selvagem, o turismo de aventura, o turismo cultural e outros segmentos turísticos que valorizam o patrimônio natural e cultural são alternativas viáveis para o município que guarda rica memória e concentra alta diversidade cultural, paisagística e biológica. Em função de sua localização estratégica próximo a Bonito e Jardim, e também por integrar a Região Turística Bonito- Serra da Bodoquena, podem ser articuladas iniciativas e parcerias político-empresariais para aumentar o desenvolvimento do ecoturismo regional. Além disso, pela cultura de integração histórica com o Paraguai, roteiros de ecoturismo e turismo cultural integrados entre os dois países seriam, certamente, exitosos.

Estão catalogadas aproximadamente 400 espécies de aves para Porto Murtinho, muitas das quais de influência do Chaco, ou seja, que apresentam distribuição geográfica associada a essa província fitogeográfica (BENITES et al., 2017). Algumas espécies registradas localmente podem ser conferidas na figura 4. 
Figura 4 - Registro de aves do município de Porto Murtinho, MS

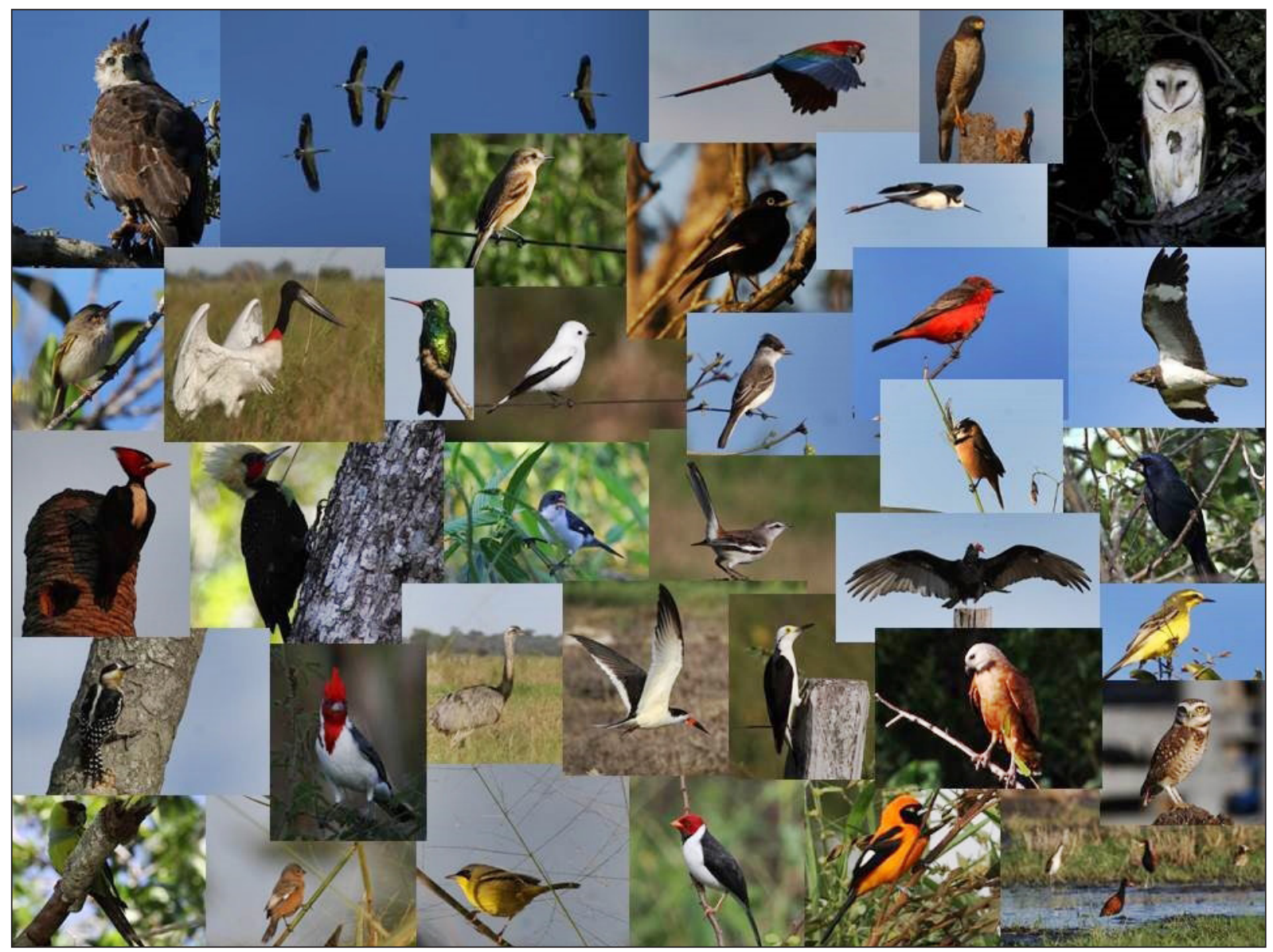

Fotos: Simone Mamede.

O turismo de observação de aves ou birdwatching, também considerado um tipo de recreação especializada, tem se expandido no mundo inteiro e os países da América do Sul têm se consagrado dentre os destinos preferidos. A avifauna pode motivar o turismo como um elemento de conservação da natureza, proporcionando incentivos econômicos, provando que a biodiversidade pode representar importante ativo socioeconômico e ambiental e se manter no médio e longo prazo.

As atividades contemplativas da biodiversidade, podem representar inovação às práticas de desenvolvimento econômico local assegurando ainda, benefícios sociais e ambientais. O turismo pode tanto contribuir para potencializar e dinamizar a economia local e regional e também influenciar políticas públicas para o próprio turismo e para a conservação ambiental. Como a região integra área fronteiriça com o Paraguai, o turismo de observação de vida selvagem no Corredor Bioceânico pode contribuir para potencializar esse segmento, tornando-o superlativo na região e ampliando sensivelmente a conservação da biodiversidade e o desenvolvimento sustentável.

\section{CONSIDERAÇÕES FINAIS}

Os ciclos econômicos de grande pujança e repercussão observados sofreram queda vertiginosa e impuseram transformações não apenas no setor econômico, mas, igualmente, nos contextos social e ambiental, confirmando que práticas insustentáveis nos modos de produção 
acarretam vida curta aos negócios e ao desenvolvimento geral. Erva-mate, tanino, pecuária bovina e turismo de pesca foram, sem dúvida, elementos preponderantes na dinâmica populacional e importantes na estruturação sócioespacial. Os dois últimos vigentes até esta data.

No entanto, é possível empreender modelos de desenvolvimento e uso da terra que incluam amplamente e estimulem a população a engajar-se na construção de territórios sustentáveis sem que haja exaustão dos bens naturais, na forma de matéria-prima. É preciso pensar nos estoques naturais que dão suporte a toda a dinâmica viva, considerando humanos e não humanos.

A movimentação política e a circulação de notícias midiáticas sobre a implantação do corredor foram suficientes para se gerar, nos últimos meses, aquecimento do mercado imobiliário e especulação de terras onde se propagam as oportunidades para expansão agrícola e pecuária proporcionada pelo Corredor. Apesar da expectativa, até eufórica de alguns, com a implantação do Corredor Bioceânico, é preciso um olhar cauteloso para que Porto Murtinho não se torne apenas uma cidade portuária per se.

Não se trata apenas de empreender um novo traçado para um corredor de escoamento produtivo, mas um corredor que deverá atravessar o único reduto de Chaco no Brasil e a maior planície continental alagável do planeta responsável por sustentar alta biodiversidade e na qual comunidades se estruturaram, convivem e desenvolvem relações socioculturais desde tempos remotos. A expansão agrícola, cujo manejo habitual se utiliza de cargas significativas de agrotóxicos para manutenção e crescimento, pode comprometer a saúde dos ecossistemas pantaneiros, visto se tratar de ambientes alagáveis perenes e intermitentes nos quais o tempo residual da água é demorado e dinâmico. O município tem figurado dentre os principais supressores de Cerrado e de vegetação nativa nos últimos anos em favor do crescimento da pecuária.

Que se esclareça, no entanto, que não é o intuito deste estudo impor atrasos ao desenvolvimento local e regional, mas alertar para um tipo de desenvolvimento que seja realmente sustentável. Portanto, evitar reducionismos e formas de desenvolvimento hegemônicos, de acumulação de riquezas e injustiças social e ambiental são ações imperativas para a continuidade das gerações e conservação dessa região de fronteira.

O ecoturismo, o artesanato, a valorização cultural e outras formas de produção sustentável, com valorização de insumos naturais, podem representar alternativas de múltipla sustentação, com garantias de economicidade, protagonismo social e uso responsável dos bens naturais na região do Corredor Bioceânico.

\section{REFERÊNCIAS}

AB'SABER, AZIZ. Brasil: paisagens de exceção: o litoral e o Pantanal Mato-grossense- patrimônios básicos. Cotia: Ateliê editorial, 2006.

ALMEIDA, Cleibson A.; SELEME, Robson; CARDOSO-NETO, João. Rodovia transoceânica: uma alternativa logística para o escoamento das exportações da soja brasileira com destino à China. Revista Economia e Sociologia Rural, Brasília, v. 51, n. 2, p. 351-68, jan./jun. 2013.

ALVES, Gilberto L. Arte, artesanato e desenvolvimento regional: temas sul-matogrossenses. Campo Grande: UFMS, 2014.

ALVES, Gilberto L. A casa comercial e o capital financeiro em Mato Grosso, 1870-1929. Campo Grande: Uniderp, 2005. 
ASSINE, Mario L.; SILVA, Aguinaldo. Contrasting fluvial styles of the Paraguay River in the northwestern border of the Pantanal wetland, Brazil. Geomorphology, Trondheim, v. 113, n. 3-4, p. 189-99, 2009.

BENITES, Maristela; MAMEdE, Simone; CARVALHO, Guto; ALHO, Cleber J. R. Assessment of avian occurrence in the Brazilian Chaco. International Journal of Avian \& Wildlife Biology, Oklahoma, v. 2, n. 4, p. 99-113, 2017.

BRAND, Antônio; FERREIRA, Eva M. L.; ALMEIDA, Fernando A. A. Os Kaiowá e Guarani em tempos da Cia. Matte Larangeira: negociações e conflitos. In: SIMPÓSIO NACIONAL DE HISTÓRIA, 23., Londrina. Anais eletrônicos [...]. São Paulo: Associação Nacional de História, 2005. Disponível em: http://www.snh2011. anpuh.org/resources/anais/anpuhnacional/S.23/ANPUH.S23.0129.pd. Acesso em: 10 fev. 2019.

BRASIL. Ministério do Meio Ambiente. Portaria n. 443, de 17 de dezembro de 2014. Lista nacional oficial de espécies da flora ameaçadas de extinção. Disponível em: http://cncflora.jbrj.gov.br/portal/static/pdf/ portaria_mma_443_2014.pdf. Acesso em: 12 nov. 2018.

BRASIL. Ministério do Turismo. Ecoturismo: orientações básicas. 2. ed. Brasília: Ministério do Turismo, 2010.

BRASIL. Sistema Nacional de Unidades de Conservação da Natureza (SNUC). Lei n. 9.985, de 18 de julho de 2000. Institui o Sistema Nacional de Unidade de Conservação da Natureza. Diário Oficial [da] República Federativa do Brasil, Brasília, DF, 19 jul. 2000. Seção 1, p. 1.

CENTENO, Carla V. A educação e trabalho na fronteira de Mato Grosso: estudo histórico sobre o trabalhador ervateiro (1870-1930). Campo Grande: UFMS, 2008.

CORIOLANO, L. N. M. T. O turismo comunitário no nordeste brasileiro. In: BARTHOLO, Roberto; SANSOLO, Davis G.; BURSZTYN Ivan (Orgs.). Turismo de Base Comunitária: diversidade de olhares e experiências brasileiras. Rio de Janeiro: Letra e Imagem, 2009. p. 277-88, Disponível em: http://www.turismo.gov. $\mathrm{br} / \mathrm{sites} /$ default/turismo/o_ministerio/publicacoes/downloads_publicacoes/TURISMO_DE_BASE_ COMUNITxRIA.pdf. Acesso em: 10 fev. 2019.

CORRÊA, Valmir B.; CORRÊA, Lúcia S. O dilema da produção de tanino na fronteira Brasil-Paraguai. Albuquerque - Revista de História, Campo Grande, v. 1, n. 1, p. 55-75, jan./jun. 2009.

ESSELIN, Paulo M. A pecuária bovina no processo de ocupação e desenvolvimento econômico do Pantanal sul-mato-grossense, 1830-1910. Dourados: Edufgd, 2011.

INSTITUTO BRASILEIRO DE GEOGRAFIA E ESTATÍSTICA (IBGE.). Manual técnico da vegetação brasileira: sistema fitogeográfico, inventário das formações florestais e campestres, técnicas e manejo de coleções botânicas, procedimentos para mapeamentos. Manuais Técnicos em Geociências, n. 1. 2. ed. rev. ampl. Rio de Janeiro: IBGE, 2012.

INSTITUTO DE MEIO AMBIENTE DE MATO GROSSO DO SUL (IMASUL). Unidades de Conservação de Mato Grosso do Sul. Campo Grande, [s.d.]. Disponível em: http://www.imasul.ms.gov.br/setores/gerencias/ unidades-de-conservacao/. Acesso em: 12 nov. 2018.

LE BOURLEGAT, Cleonice A. Campo Grande e o estado do Mato Grosso do Sul no centro do Corredor sul-americano dos litorais atlântico e pacífico. Multitemas, Campo Grande, n. 8, p. 169-90, jan./jul. 2016.

LEFEBVRE, Henri. O direito à cidade. São Paulo: Centauro, 2001.

LIMA, Maria Margareth E. R. O resgate de Porto Murtinho. Ensaios e Ciência: Ciências Biológicas, Agrárias e da Saúde, v. 4, n. 3, p. 135-43, dez. 2000. 
OLIVEIRA, Jorge E.; ESSELIN, Paulo M. Uma breve história (indígena) da erva-mate na região platina: da Província do Guairá ao antigo sul de Mato Grosso. Espaço Ameríndio, Porto Alegre, v. 9, n. 3, p. 278-318, jul./dez. 2015.

PORTO-GONÇALVES, Carlos W. A ecologia política na América Latina: reapropriação social da natureza e reinvenção dos territórios. Revista Internacional Interdisciplinar Interthesis, Florianópolis, v. 9, n. 1, p. 16-50, jul. 2012.

POTT, Arnildo; OLIVEIRA, Ademir K. M.; DAMASCENO-JÚNIOR, Geraldo A; SILVA, J. S. V. Plant diversity of the Pantanal wetland. Brazilian Journal of Biology, São Carlos, v. 71, n. 1, p. 265-73, 2011.

POTT, Arnildo; POTT, Vali J.; DAMASCENO-JÚNIOR, Geraldo A. Fitogeografia do Pantanal. In: CONGRESSO LATINO AMERICANO DE ECOLOGIA, 3; CONGRESSO DE ECOLOGIA DO BRASIL, 9., São Lourenço. Anais eletrônicos [...]. São Paulo: Sociedade de Ecologia do Brasil, 2009. Disponível em: http://ecologia.ib.usp. br/seb-ecologia/2009/resumos_professores/arnildo_pott.pdf. Acesso em: 10 dez. 2018.

PRADO, Darién E. What is the Gran Chaco vegetation in South America? I. A review. Contribution to the study of flora and vegetation of the Chaco V. Candollea, Genebra, v. 48, n. 1, p. 145-72, 1993.

PRADO, Darién E.; GIBBS, Peter E.; POTT, Arnildo. POTT, Vali, J. The Chaco-Pantanal transition in southern Mato Grosso, Brazil. In: FURLEY, Peter A; PROCTOR, John; RATTER, John A. (Ed.). Nature and dynamics of forest-savanna boundaries. 5. ed. London: Chapman \& Hall, 1992.

ROMERO, Maiara C.; RODRIGUES, Marlon L. A língua guarani japorá: uma questão de identidade. WebRevista SOCIODIALETO, Campo Grande, v. 5, n. 13, p. 73-89, jul. 2014.

SANTOS, Milton. A natureza do espaço: técnica e tempo, razão e emoção. 4. ed. São Paulo: EDUSP, 2012.

SARMIENTO, Guillermo. Ecological and floristic convergences between seasonal plant formations of Tropical and Subtropical South America. Journal of Ecology, London, v. 60, n. 2, p. 367-410, 1972.

SECRETARIA DE ESTAdO DE MEIO AMBIENTE E DESENVOLVIMENTO ECONÔMICO (SEMADE). Perfil Estatístico de Mato Grosso do Sul 2015 - ano base: 2015. Campo Grande: SEMADE, 2016.

SILVA, João V.; CAPUTO, Ana C. B. Localização e distribuição da vegetação Savana Estépica (Chaco) no Pantanal brasileiro. In: SIMPÓSIO DE GEOTECNOLOGIAS NO PANTANAL, 3., Cáceres. Anais eletrônicos [...]. Cáceres: Embrapa Informática Agropecuária/INPE, 2010. Disponível em: https://ainfo.cnptia.embrapa. br/digital/bitstream/item/23282/1/p226.pdf. Acesso em: 2 set. 2018.

SILVA, Marta P.; MAURO, Rodiney A.; ABDON, Myrian; SILVA, João dos .Santos. V. Estado de Conservação do Chaco (Savana Estépica) brasileiro. In: SIMPÓSIO NACIONAL CERRADO, 9.; SIMPÓSIO INTERNACIONAL SAVANAS TROPICAIS, 2., Brasília, 2-17 out. 2008. Anais eletrônicos [...] Brasília: Embrapa Cerrados, 2008. Disponível em: http://simposio.cpac.embrapa.br/simposio\%20em\%20pc210\%20(Pc210)/trabalhos_ pdf/00789_trab1_ap.pdf. Acesso em: 2 set. 2018.

SILVESTRINI, Rubens; WEINGARTNER, Alisolete; TACHIBANA, Luã. A tríade Guerra do Paraguai-erva mateterritório: a contribuição da llex paraguariensis para a formação da fronteira do território brasileiro pósguerra. Revista Argamassa, Campo Grande, v. 1, n. 2, p. 17-29, maio/ago. 2018.

SODRÉ, Nelson W. Oeste: ensaio sobre a grande propriedade pastoril. São Paulo: J. Olympio, 1941. 


\section{Sobre os autores:}

Maristela Benites - Mestre em Ecologia e Conservação e Bióloga pela Universidade Federal de Mato Grosso do Sul (UFMS). Acadêmica do curso de Geografia, bacharelado, da Universidade Estadual de Mato Grosso do Sul (UEMS), unidade de Campo Grande. Pesquisadora e educadora no Instituto Mamede de Pesquisa Ambiental e Ecoturismo. E-mail: maris.benites@gmail.com, Orcid: http://orcid.org/0000-0003-0024-1122

Simone Mamede-Doutora em Meio Ambiente e Desenvolvimento Regional pela Universidade para o Desenvolvimento do Estado e da Região do Pantanal (UNIDERP-Anhanguera). Mestre em Meio Ambiente e Desenvolvimento Regional. Especialista em Ecoturismo e Educação Ambiental. Graduada em Biologia e Gestão do Turismo. Pesquisadora e educadora no Instituto Mamede de Pesquisa Ambiental e Ecoturismo. Pesquisadora em Biodiversidade. E-mail: simone.mamede1@gmail.com, Orcid: http://orcid.org/0000-0002-7785-320X

Carla Villamaina Centeno - Doutora em Educação pela Universidade Estadual de Campinas. Mestre em Educação pela Universidade Federal de Mato Grosso do Sul. Graduada em História pela Faculdades Unidas Católicas de Mato Grosso. Professora efetiva da Universidade Estadual de Mato Grosso do Sul. E-mail: carla.centeno@uol.com.br, Orcid: http://orcid.org/0000-0002-7275-0367

Gilberto Luiz Alves - Doutor e estudos de pós-doutorado em Educação pela Universidade Estadual de Campinas. Mestre em Educação pela Universidade Federal de São Carlos. Graduado em Pedagogia pela Universidade Estadual Paulista "Júlio de Mesquita Filho". Professor da Universidade Federal de Mato Grosso do Sul. E-mail: gilbertoalves9@uol.com.br, Orcid: http://orcid.org/0000-0001-9672-1459 